\title{
Understanding the Methodological Issues and Solutions in the Research Design of Stroke Caregiving Technology
}

\begin{abstract}
Elton H. Lobo ${ }^{1,2 \star}$, Anne Frølich ${ }^{2,3}$, Lene J. Rasmussen ${ }^{4,5}$, Patricia M. Livingston ${ }^{6}$, John Grundy ${ }^{7}$, Mohamed Abdelrazek ${ }^{1}$ and Finn Kensing ${ }^{8}$

'School of Information Technology, Faculty of Science, Engineering and Built Environment, Deakin University, Geelong, VIC, Australia, ${ }^{2}$ Section of General Practice, Department of Public Health, University of Copenhagen, Copenhagen, Denmark, ${ }^{3}$ Innovation and Research Centre for Multimorbidity, Slagelse Hospital, Region Zealand, Denmark, ${ }^{4}$ Department of Cellular and Molecular Medicine, University of Copenhagen, Copenhagen, Denmark, ${ }^{5}$ Center for Healthy Aging, University of Copenhagen, Copenhagen, Denmark, ${ }^{6}$ Faculty of Health, Deakin University, Geelong, VIC, Australia, ${ }^{7}$ Faculty of Information Technology, Monash University, Clayton, VIC, Australia, ${ }^{8}$ Department of Computer Science, University of Copenhagen, Copenhagen, Denmark
\end{abstract}

The rise in the number of cases of stroke has resulted in a significant burden on the healthcare system. As a result, the majority of care for the person living with stroke occurs within the community, resulting in caregivers being a central and challenged agent in care. To better support caregivers during the recovery trajectory poststroke, we investigated the role of health technologies to promote education and offer various kinds of support. However, the introduction of any new technology comes with challenges due to the growing need for more user-centric systems. The integration of user-centric systems in stroke caregiving has the potential to ensure long-term acceptance, success, and engagement with the technology, thereby ensuring better care for the person living with stroke. We first briefly characterize the affordances of available technologies for stroke caregiving. We then discuss key methodological issues related to the acceptance to such technologies. Finally, we suggest user-centered design strategies for mitigating such challenges.

Keywords: stroke, caregiver, design methodology, technology, issues, solutions, user-centered design

\section{INTRODUCTION}

The increase in healthcare costs has resulted in the transition of stroke care from inpatient to community-based services (1). As a result, caregivers are expected to take on the responsibility to provide essential support to people living with stroke (2). However, the lack of coordinated postdischarge care leaves the caregiver and the person living with stroke to often feel abandoned and unsupported (3). This leads to an increase in burden or strain on the caregiver (4). Research highlights that the burden of caregiving is a multidimensional concept that includes several adverse effects on the physical, psychological, social, and financial functioning of the caregiver (5). Because of this, the caregiver is at risk of impaired health, suboptimal cognitive functioning, poor mental health, disruption in household roles, reduced quality of life, and changes to important life goals and future plans (6). Therefore, there is a need to transform care support, increase access, improve quality of care, and reduce cost of care throughout the disease trajectory. 
Recent advances in health information technologies have been gaining interest in supporting caregivers in stroke as they utilize a combination of information and communication technologies to provide a more practical, affordable, and user-friendly solution (7). Such technological solutions are unrestricted by the place or time and focus on empowering its user to improve participation, decision making, and commitment to treatment, thus improving overall health outcomes (8).

While health information technology solutions have the potential to better support caregivers, the process of providing such care within the community has proven to be a challenge (9) that needs to be considered in the design of any care support system. These challenges need to be addressed to ensure new technological solutions are acceptable to their target end users. However, to date, researchers do not fully understand the scope and complexity of including users in the design of the care support system (10). This leads to issues in adoption of the solutions proposed.

Our objective is to better inform future researchers on means to address this issue. To achieve this objective, we first characterize the potential of health technologies in stroke caregiving and issues faced by the user in accessing and using these technologies. We then review the methodological practices implemented to design these technologies. In doing so, we highlight the key methodological issues reported in the design of stroke caregiving technology. We also discuss various concerns addressed by the researchers during the development of such technological systems. Finally, we suggest user-centered design strategies that have proven instrumental for mitigating such challenges in the healthcare domain.

\section{HEALTH TECHNOLOGIES IN STROKE CAREGIVING}

Health technologies in stroke caregiving consist of different means to promote interaction using web (11-13), Information and Communication Technology (ICT) $(14,15)$, mHealth (1624), and telehealth systems (22). Web-based systems are those that are delivered through a browser on different devices such as computer, television, or mobile, with the requirement for access to the internet to use the service (11-13). ICT systems rely on a communication technology to connect numerous different devices $(14,15)$, mHealth relies on mobile devices (16-24), and telehealth relies on telecommunication devices such as telephone to promote interaction and support (22). The intention of these systems is to promote healthcare delivery and exchange over a wider geographic distance, thereby ensuring more effective and efficient care to the person living with stroke (11-24).

Technologies for stroke caregiving highlight the potential of these interventions in providing the caregiver with education, communication, monitoring, and rehabilitation support tools to promote better care for the person living with stroke (11-24). These technologies are designed to address specific needs of the caregiver identified through the use of surveys (17-19), interview

Abbreviations: mHealth, mobile health; App, application; PD, participatory design; CSCW, computer-supported cooperative work.
(14-18), focus groups $(11,14,16,17)$, observations $(14,15,18)$, and/or best practices from evidence-based literature (12, 13, 2024). Caregivers adopting these technologies are satisfied with the ability to use them at any given place or time, while being able to interact and share information with people having similar experiences $(13,17,18)$. Moreover, they allow for the caregiver to be reassured about their practices and techniques during recovery (17). Overall, the literature reports that the technologies employed to date have been effective $(11,18,19)$ and acceptable $(13,17-19)$ in helping to support and manage the person living with stroke.

\section{METHODOLOGICAL ISSUES IN STROKE CAREGIVING TECHNOLOGY}

Technology for stroke caregiving is a useful tool to improve efficiency and quality of rehabilitation care (25). Despite widespread agreement of the potential of stroke caregiving technology in care and recovery, several researchers rely mostly on evidence-based approaches for the design of stroke caregiving technology $(12,13,20-24)$. The aim of such processes is to ensure conscientious, explicit, and judicious use of best evidence guidelines created by credible research or best-practice guidelines or through systematic reviews and/or meta-analysis to make critical decisions regarding the design of the system (26). While theoretical models can form a solid foundation in the design of new technologies, the lack of understanding and ability to provide direct attention to the user suggests that it may be less effective for people with different chronic conditions (27). Furthermore, there are numerous concerns regarding the level of use by stroke caregivers. As a result, several research-based stroke caregiving technologies are not yet fully realized in commercial markets for use by caregivers of those with stroke (28).

The lack of realization of stroke caregiving technology in the market raises concerns around the methods and evaluation procedures in their design. These are exacerbated by the structure and design of the system and means by which the user interacts with it (29). Issues surrounding the structure, design, and user interaction could be better addressed through a detailed understanding of the user capabilities. These need to be acquired from user responses that cannot be determined through evidence-based theories (29). Moreover, only a few studies focus on understanding the range of factors associated with the interaction of the user and the system in stroke caregiving technology literature $(13,14,17,18,23,30)$ and more focus on its ability to meet the caregivers' needs in recovery (13-18, 20-23, 31-35).

While stroke caregiving technology should be designed to support the caregivers' needs during recovery, it must also consider the range of factors toward implementing necessary functionalities. This is because it could create risk for not only the caregiver but also the patients and medical professionals (36). For example, providing general information regarding the disease and not specific information related to the patient's condition could impact the quality of care. Therefore, the system implemented needs to account for an easy-to-use design, while 
also ensuring the data presented to the user are effective, easy to comprehend, and free from errors (37). Moreover, information provided to the user should be based on their specific needs (38), thereby limiting any confusion during care and recovery. These factors are similar to the studies by Cameron et al. (2), Creasy et al. (39), and Krieger et al. (40), which all suggest the need of caregivers to have personalized information that are easy to comprehend $(2,40-42)$ and are delivered at appropriate times $(2,42-45)$. While technology has the potential to provide personalized information and support (such as medication delivery, self-monitoring, and so on) through the use of contextaware systems (46); it has not yet been realized for stroke caregiving technology. Hence, it is clear that there is a lack of understanding of the available technology and user needs, which results in issues during the design and implementation of such technologies.

\section{USER-CENTERED DESIGN TO IMPROVE STROKE CAREGIVING TECHNOLOGY}

The limitations of current and future stroke caregiving technologies can be reduced by better promoting user involvement in its design, development, and implementation (25). One such approach is user-centered design (47). The concept of user-centered design offers tangible, scalable, and reproducible methods to include relevant users in the healthcare process (48). Through the better inclusion of target end users during development, the developers can focus on observing and understanding the planning of care and recovery trajectories and tailor the technology to support the needs of the user during this process. This extends beyond traditional practices that tend to rely on evidence-based literature $(13,21-24)$ to develop and implement technologies to support stroke caregivers. However, it is important to note that the practices involved in user-centered design are not new to healthcare. For example, the development of medicines undergoes several modifications including understanding its effects and impact on the user prior to making it public and ensuring adoption. None of these medications is developed entirely based on evidence-based literature or personal experiences. This is similar to what user-centered design aims to achieve, but with technology solutions.

While some studies $(13,14,17,18,23,30,35)$ have considered iterative user-centered design approaches and participatory design (PD) practices, the extent of implementation of these methods has not been fully described in the literature. For example, Sureshkumar et al. (18) focused on a user-centered design methodology for the design of an educational-based mobile application to support stroke caregivers; however, there is no explanation in the study of how they investigate users' needs and capabilities. Such knowledge could be used to conclude that educational support was the only need of stroke caregivers and that they are comfortable using a mobile-based application. These assumptions (i.e., education support delivered through mobile) are not always the case as highlighted in the studies involving the needs assessment (49) and technological capabilities (47) of caregivers in stroke. Similar assumptions were implemented in other user-centered design studies $(14,17,23,31)$, where the full breadth of caregivers' needs and capabilities were not investigated prior to designing the intervention. This led to issues in the initial design of the technology and a lack of integration of technology in the normal care practices during recovery as discussed in the previous section.

The lack of proper implementation of user-centered design practices could be due to three challenges: (i) understanding users' practices and needs, (ii) the codesign of innovative and sustainable solutions, and (iii) the technical and organizational implementation. These challenges were identified based on literature findings (50-53). This is important, as the success of any user-centered design study is dependent on a genuine user participation (54). Through the inclusion of users, it is possible to generate new insights and ideas that can embrace ambiguity and provide structured systematic innovation in public health. The healthcare literature has also highlighted the importance of user-centered design and the role of users in developing sustainable systems by creating actionable strategies to test, refine, and integrate the solution in the individual's daily activities (55). Hence, there is a need to suggest mitigation strategies in terms of guiding principles and tools and techniques that can support stroke caregivers, as shown in Table 1. These recommendations are based on our own and colleagues' experiences, some of which are gained in healthcare projects conducted to support different chronic conditions. However, these studies do not account for caregivers and would need to be studied further to gain greater insights to better support these individuals.

\section{Challenge 1: Developing a Proper Understanding of Users' Practices and Needs}

Stroke caregivers often demand to be involved in the decisionmaking process in care to ensure the practices implemented consider the survivors and their individual needs (39). While user-centered design allows for a clear understanding of user needs from different groups of users including primary, secondary, and some tertiary users (29), conducting research with older adults could be challenging (59) as the average age of stroke caregivers is expected to be $>55$ years (60). However, Wilkinson and Cornish (61) argue that user-centered design, especially PD approach, could be used to involve the real-world users in the design and development process as it ensures tools promote increased participation irrespective of the age.

PD draws from ethnographically inspired fieldwork (i.e., interviews, observations, workshops, thinking aloud, and so on) during a normal workday of the user (62) to gain firsthand experiences with current work practices (57). Through an understanding of current work practices, researchers can form design engagements according to local needs and respond to issues defined by the intended user within the community (63). A primary concern in PD is that it consists of the distribution of power, making it difficult to utilize technology to meet the needs of the intended user (56). Hence, much 
TABLE 1 | Challenges, guiding principles, and tools and techniques in implementing user-centered design.

\begin{tabular}{|c|c|c|}
\hline Strategy & Guiding principles & Primary tools and techniques \\
\hline $\begin{array}{l}\text { Developing a proper } \\
\text { understanding of a diverse } \\
\text { set of groups of users' } \\
\text { practices and needs }\end{array}$ & $\begin{array}{l}\text { Participatory design (PD) literature suggests genuine user participation (56) and } \\
\text { getting firsthand experience with current work practices (57). } \\
\text { Computer-supported cooperative work (CSCW) literature recommends, e.g., aligning } \\
\text { concerns, focus on needs for awareness (10,52), and being cautious expecting one } \\
\text { group to deliver valuable data without getting valuable feedback (58) }\end{array}$ & $\begin{array}{l}\text { Ethnographically inspired fieldwork: } \\
\text { interviews, observations, workshops, } \\
\text { thinking aloud, and so on }\end{array}$ \\
\hline $\begin{array}{l}\text { Codesign of innovative and } \\
\text { sustainable solutions }\end{array}$ & $\begin{array}{l}\text { PD literature recommend concurrent design of coherent visions for change } \\
\text { (information technology systems, work organization, and mapping out the } \\
\text { qualifications needed) and that special attention is given to anchoring visions with } \\
\text { users, managers, and those responsible for the technical and organizational } \\
\text { implementation (56) }\end{array}$ & $\begin{array}{l}\text { Iterations of workshops, scenarios, } \\
\text { and prototyping }\end{array}$ \\
\hline $\begin{array}{l}\text { Technical and organizational } \\
\text { implementation }\end{array}$ & $\begin{array}{l}\text { Respect or challenge existing technical and organizational infrastructures - and be } \\
\text { prepared to take the consequences (56) }\end{array}$ & $\begin{array}{l}\text { Move secure prototypes to a living } \\
\text { laboratory (53) setting for further } \\
\text { design, development, and test before } \\
\text { rollout }\end{array}$ \\
\hline
\end{tabular}

of the existing body of research considers the inclusion of Computer-supported cooperative work to limit unforeseen tensions and ensure researchers shape the collaborative design engagements to align with a diverse group of users' needs and practices (63), while being cautious about expecting one group to deliver valuable data without getting valuable feedback (58).

\section{Challenge 2: Codesign of Innovative and Sustainable Solutions}

In user-centered design, once the user needs and requirements are identified, a process of design, evaluate, and reiterate is carried out. This iterative process refines a software prototype based on a collaboration between intended users and the researchers to eventually better support the intended user (i.e., caregiver) in their daily activities (64). Moreover, it allows for the researcher to identify possible usability errors that may impact the users' ability to interact with the system (65) during recovery and care of the person living with stroke.

The PD process during codesign relies on two principal values, participation and democracy, to involve a range of individuals with diversity in experiences and knowledge $(66,67)$. These principal values are expected to be maintained throughout the design process, thereby enabling trust and facilitating mutual learning and commitment toward developing a system that meets the needs of the intended user (50). One way to practice these values is by facilitating a variety of workshops, storyboards, mock-ups, probes, scenarios, walk-throughs, games, collaborative prototyping, etc. $(66,68,69)$. These are to ensure equal collaboration in the design of innovative and sustainable solutions based on individual knowledge and perspectives (70).

\section{Challenge 3: Technical and Organizational Implementation}

The design of any technology in healthcare should focus both on technology and healthcare outcomes. Past healthcare literature focuses on only one aspect (i.e., health or technology) (55), which has raised some concerns in the past regarding its sustainability or adherence over extended periods. Hence, to create sustainable solutions for stroke caregivers, it is necessary for the system to meet the visions of the different stakeholders involved in the care (10), such as caregivers, survivors, medical professionals, rehabilitation specialists, etc. This is typically achieved through multiple iterations where the goals, needs, and potentials are constantly evaluated, leading to the formation of successful systems for recovery and care (71). According to Schuurman and De Marez (72) and Andersen et al. (73), it is possible to perform such practices through the use of living laboratories. The living laboratory is a concept that encompasses diverse concepts driven by local innovation activities stated by different stakeholders to improve their everyday lives (74). In general, living laboratories include codesign test beds, collaboration, and knowledge management tools to support interaction between multiple stakeholders, communities, and organizations (75) to create sustainable technological solutions that improve everyday life $(74,75)$, therefore allowing for the researcher to identify issues related to the technical and organizational implementation while being prepared to manage its consequences (56).

\section{CONCLUSIONS AND FUTURE RESEARCH}

In conclusion, there are several issues highlighted in the stroke caregiving technology literature that need to be addressed to promote better success, long-term acceptance, and engagement of the designed solutions. To achieve these goals, future research in stroke caregiving technology needs to focus more on improving user participation in the design and development through proper understanding of the user practices and needs, inclusion of codesign solutions, and technical and organizational implementation. These have been demonstrated in the literature considering $\mathrm{PD}$ and computer-supported collaborative work approaches. 


\section{DATA AVAILABILITY STATEMENT}

The original contributions presented in the study are included in the article/supplementary material, further inquiries can be directed to the corresponding author/s.

\section{AUTHOR CONTRIBUTIONS}

EL initiated this study to address the methodological issues in stroke caregiving technology through past literature studies in healthcare intervention design. EL performed this study under the supervision of FK, who provided critical comments

\section{REFERENCES}

1. Kitzman P, Hudson K, Sylvia V, Feltner F, Lovins J. Care coordination for community transitions for individuals post-stroke returning to low-resource rural communities. J Community Health. (2017) 42:565-72. doi: 10.1007/s10900-016-0289-0

2. Cameron JI, Naglie G, Silver FL, Gignac MA. Stroke family caregivers' support needs change across the care continuum: a qualitative study using the timing it right framework. Disabil Rehabil. (2013) 35:31524. doi: 10.3109/09638288.2012.691937

3. Pindus DM, Mullis R, Lim L, Wellwood I, Rundell AV, Abd Aziz NA, et al. Stroke survivors' and informal caregivers' experiences of primary care and community healthcare services - A systematic review and meta-ethnography. PLoS ONE. (2018) 13:e0192533. doi: 10.1371/journal.pone.0192533

4. Akosile CO, Banjo TO, Okoye EC, Ibikunle PO, Odole AC. Informal caregiving burden and perceived social support in an acute stroke care facility. Health Qual Life Outcomes. (2018) 16:57. doi: 10.1186/s12955-0180885-z

5. Panzeri A, Rossi Ferrario S, Vidotto G. Interventions for psychological health of stroke caregivers: a systematic review. Front Psychol. (2019) 10:2045. doi: 10.3389/fpsyg.2019.02045

6. Chen P, Fyffe DC, Hreha K. Informal caregivers' burden and stress in caring for stroke survivors with spatial neglect: an exploratory mixed-method study. Top Stroke Rehabil. (2017) 24:24-33. doi: 10.1080/10749357.2016.1186373

7. Aldehaim AY, Alotaibi FF, Uphold CR, Dang S. The impact of technologybased interventions on informal caregivers of stroke survivors: a systematic review. Telemed J E Health. (2016) 22:223-31. doi: 10.1089/tmj.2015.0062

8. van den Heuvel JF, Groenhof TK, Veerbeek JH, van Solinge WW, Lely AT, Franx A, et al. eHealth as the next-generation perinatal care: an overview of the literature. J Med Internet Res. (2018) 20:e202. doi: 10.2196/jmir.9262

9. Kuluski K, Ho JW, Hans PK, Nelson M. Community care for people with complex care needs: bridging the gap between health and social care. Int J Integr Care. (2017) 17:2. doi: 10.5334/ijic.2944

10. Andersen TO, Bansler JP, Kensing F, Moll J, Mønsted T, Nielsen KD, et al. Aligning concerns in telecare: three concepts to guide the design of patient-centred E-health. Comput Supported Coop Work. (2019) 28:1039-72. doi: 10.1007/s10606-018-9309-1

11. Smith GC, Egbert N, Dellman-Jenkins M, Nanna K, Palmieri PA. Reducing depression in stroke survivors and their informal caregivers: a randomized clinical trial of a Web-based intervention. Rehabil Psychol. (2012) 57:196206. doi: 10.1037/a0029587

12. Stone K. Enhancing preparedness and satisfaction of caregivers of patients discharged from an inpatient rehabilitation facility using an interactive website. Rehabil Nurs. (2014) 39:76-85. doi: 10.1002/rnj.123

13. Blanton S, Dunbar S, Clark PC. Content validity and satisfaction with a caregiver-integrated web-based rehabilitation intervention for persons with stroke. Top Stroke Rehabil. (2018) 25:16873. doi: 10.1080/10749357.2017.1419618

14. Mawson S, Nasr N, Parker J, Zheng H, Davies R, Mountain G. Developing a personalised self-management system for post stroke rehabilitation; utilising that enabled a clear presentation of findings within the final manuscript. Further, EL drafted the manuscript that was revised by FK, MA, AF, LR, PL, and JG. All authors contributed to the article and approved the submitted version.

\section{FUNDING}

This study was supported through doctoral scholarships from the School of Information Technology, Deakin University, and the Department of Public Health, University of Copenhagen. Further, the research team would like to acknowledge JG, supported by ARC Laureate Fellowship FL190100035. a user-centred design methodology. Disabil Rehabil Assist Technol. (2014) 9:521-8. doi: 10.3109/17483107.2013.840863

15. Nasr N, Leon B, Mountain G, Nijenhuis SM, Prange G, Sale P, et al. The experience of living with stroke and using technology: opportunities to engage and co-design with end users. Disabil Rehabil Assist Technol. (2016) 11:65360. doi: 10.3109/17483107.2015.1036469

16. Kamwesiga JT, Eriksson GM, Tham K, Fors U, Ndiwalana A, von Koch L, et al. A feasibility study of a mobile phone supported family-centred ADL intervention, F@ ce $\mathrm{TM}^{\mathrm{TM}}$, after stroke in Uganda. Globalization Health. (2018) 14:82. doi: 10.1186/s12992-018-0400-7

17. Caunca MR, Simonetto M, Hartley G, Wright CB, Czaja SJ. Design and usability testing of the stroke caregiver support system: a mobile-friendly website to reduce stroke caregiver burden. Rehabil Nurs. (2018) 45:16677. doi: 10.1161/str.49.suppl_1.TP385

18. Sureshkumar K, Murthy G, Natarajan S, Naveen C, Goenka S, Kuper H. Evaluation of the feasibility and acceptability of the 'Care for Stroke'intervention in India, a smartphone-enabled, carer-supported, educational intervention for management of disability following stroke. BMJ Open. (2016) 6:e009243. doi: 10.1136/bmjopen-2015-009243

19. Mahmood A, Blaizy V, Verma A, Stephen Sequeira J, Saha D, Ramachandran $S$, et al. Acceptability and attitude towards a mobile-based home exercise program among stroke survivors and caregivers: a cross-sectional study. Int J Telemed Appl. (2019) 2019:5903106. doi: 10.1155/2019/5903106

20. Zhou B, Zhang J, Zhao Y, Li X, Anderson CS, Xie B, et al. Caregiver-delivered stroke rehabilitation in rural China: the RECOVER Randomized Controlled Trial. Stroke. (2019) 50:1825-30. doi: 10.1161/STROKEAHA.118.021558

21. Görlitz RA, editor. The stroke manager app-individual and mobile support for stroke patients and their caregivers. In: Proceedings of the Ninth International Conference on Management Science and Engineering Management. Berlin: Springer (2015).

22. Vloothuis J, de Bruin J, Mulder M, Nijland R, Kwakkel G, van Wegen EEH. Description of the CARE4STROKE programme: a caregiver-mediated exercises intervention with e-health support for stroke patients. Physiother Res Int. (2018) 23:e1719. doi: 10.1002/pri.1719

23. Hughes CM, Hintze A, Padilla A, Mariscal T, Warner S, Sera M, et al., editors. Development of a mHealth system for post-stroke upper limb rehabilitation in medically underserved populations: An iterative usability study. In: IEEE Global Humanitarian Technology Conference (GHTC). San Jose, CA: IEEE (2018).

24. Yan LL, Chen S, Zhou B, Zhang J, Xie B, Luo R, et al. A randomized controlled trial on rehabilitation through caregiver-delivered nurseorganized service programs for disabled stroke patients in rural china (the RECOVER trial): design and rationale. Int J Stroke. (2016) 11:823-30. doi: 10.1177/1747493016654290

25. Nam HS, Park E, Heo JH. Facilitating stroke management using modern information technology. J Stroke. (2013) 15:13543. doi: 10.5853/jos.2013.15.3.135

26. Rashid M. The question of knowledge in evidence-based design for healthcare facilities: limitations and suggestions. HERD. (2013) 6:10126. doi: $10.1177 / 193758671300600407$ 
27. Fletcher-Watson S. Evidence-based technology design and commercialisation: recommendations derived from research in education and autism. TechTrends. (2015) 59:84-8. doi: 10.1007/s11528-014-0825-7

28. Lobo EH, Frølich A, Kensing F, Rasmussen LJ, Livingston PM, Grundy J, et al. mHealth applications to support caregiver needs and engagement during stroke recovery: a content review. Res Nurs Health. (2021) 44:21325. doi: 10.1002/nur.22096

29. Lyon AR, Koerner K. User-centered design for psychosocial intervention development and implementation. Clin Psychol. (2016) 23:180-200. doi: $10.1111 /$ cpsp.12154

30. Vloothuis J, Depla M, Hertogh C, Kwakkel G, van Wegen E. Experiences of patients with stroke and their caregivers with caregiver-mediated exercises during the CARE4STROKE trial. Disabil Rehabil. (2020) 42:698704. doi: 10.1080/09638288.2018.1507048

31. Nasir MHNM, Hassan NH, Nor MKM. Participatory user centered design techniques for a web information system for stroke. In: International Symposium on Communications and Information Technologies. Vientiane (2008). p. 556-61.

32. Marziali E, Donahue P, Crossin G. Caring for others: internet health care support intervention for family caregivers of persons with Alzheimer's, stroke, or Parkinson's disease. Families Soc. (2005) 86:375-83. doi: 10.1606/1044-3894.3435

33. Pierce LL, Rupp GL, Hicks B, Steiner V. Meeting the educational needs for caregivers and survivors of stroke. Gerontol Geriatr Educ. (2003) 23:7590. doi: 10.1300/J021v23n04_07

34. Pierce LL, Steiner VL, Khuder SA, Govoni AL, Horn LJ. The effect of a Web-based stroke intervention on carers' well-being and survivors' use of healthcare services. Disabil Rehabil. (2009) 31:1676-84. doi: 10.1080/09638280902751972

35. Steiner V, Pierce LL. Building a web of support for caregivers of persons with stroke. Top Stroke Rehabil. (2002) 9:10211. doi: 10.1310/B9FE-QWEV-RM1F-FJA6

36. Sittig DF, Wright A, Coiera E, Magrabi F, Ratwani R, Bates DW, et al. Current challenges in health information technology-related patient safety. Health Informatics J. (2018) 26:181-9. doi: 10.1177/1460458218814893

37. Johnson CM, Johnson TR, Zhang J. A user-centered framework for redesigning health care interfaces. J Biomed Inform. (2005) 38:7587. doi: 10.1016/j.jbi.2004.11.005

38. De Vito Dabbs A, Myers BA, Mc Curry KR, Dunbar-Jacob J, Hawkins RP, Begey A, et al. User-centered design and interactive health technologies for patients. Comp Inform Nurs. (2009) 27:175-83. doi: 10.1097/NCN.0b013e31819f7c7c

39. Creasy KR, Lutz BJ, Young ME, Ford A, Martz C. The impact of interactions with providers on stroke caregivers' needs. Rehabil Nurs. (2013) 38:8898. doi: 10.1002/rnj.69

40. Krieger T, Feron F, Dorant E. Developing a complex intervention programme for informal caregivers of stroke survivors: The Caregivers' Guide. Scand J Caring Sci. (2017) 31:146-56. doi: 10.1111/scs.12344

41. Ang SY, Tin AS, Pavitar G, Ng WM, Lee KE, Lim LH, et al. A qualitative study into stroke caregivers' educational needs - perspectives of caregivers and healthcare professionals. Proc Singapore Healthc. (2013) 22:166-74. doi: 10.1177/201010581302200303

42. Thomas M, Greenop K. Caregiver experiences and perceptions of stroke. Health SA Gesondheid. (2008) 13:29-40. doi: 10.4102/hsag.v13i1.255

43. Smith LN, Lawrence M, Kerr SM, Langhorne P, Lees KR. Informal carers' experience of caring for stroke survivors. J Adv Nurs. (2004) 46:23544. doi: 10.1111/j.1365-2648.2004.02983.x

44. Cobley CS, Fisher RJ, Chouliara N, Kerr M, Walker MF. A qualitative study exploring patients' and carers' experiences of Early Supported Discharge services after stroke. Clin Rehabil. (2013) 27:750-7. doi: 10.1177/0269215512474030

45. Danzl MM, Harrison A, Hunter EG, Kuperstein J, Sylvia V, Maddy K, et al. "A lot of things passed me by": rural stroke survivors' and caregivers' experience of receiving education from health care providers. J Rural Health. (2016) 32:13-24. doi: 10.1111/jrh.12124

46. Yin K, Laranjo L, Tong HL, Lau AY, Kocaballi AB, Martin P, et al. Contextaware systems for chronic disease patients: scoping review. J Med Int Res. (2019) 21:e10896. doi: 10.2196/10896
47. Wentink M, van Bodegom-Vos L, Brouns B, Arwert H, Houdijk S, Kewalbansing $\mathrm{P}$, et al. How to improve eRehabilitation programs in stroke care? A focus group study to identify requirements of end-users. BMC Med Inform Decis Mak. (2019) 19:145. doi: 10.1186/s12911-019-0871-3

48. Sandholdt CT, Cunningham J, Westendorp RGJ, Kristiansen M. Towards inclusive healthcare delivery: potentials and challenges of human-centred design in health innovation processes to increase healthy aging. Int J Environ Res Public Health. (2020) 17:4551. doi: 10.3390/ijerph17124551

49. Tsai PC, Yip PK, Tai JJ, Lou MF. Needs of family caregivers of stroke patients: a longitudinal study of caregivers' perspectives. Patient Prefer Adherence. (2015) 9:449-57. doi: 10.2147/PPA.S77713

50. Kensing F, Greenbaum J. Heritage: Having a say. Routledge International Handbook of Participatory Design. New York, NY: Routledge (2013). p. 21-36.

51. Holmlid S. Participative; co-operative; emancipatory: from participatory design to service design. In: Conference Proceedings ServDes 2009; DeThinking Service; ReThinking Design; Oslo Norway 24-26 November 2009. Linköping University Electronic Press (2012). p. 105-18.

52. Fitzpatrick G, Ellingsen G. A review of 25 years of CSCW research in healthcare: contributions, challenges and future agendas. J Comp Support Cooperat Work. (2013) 22:609-65. doi: 10.1007/s10606-012-9168-0

53. Dell'Era C, Landoni P. Living lab: a methodology between user-centred design and participatory design. Creat Innov Manag. (2014) 23:13754. doi: 10.1111/caim.12061

54. Fischer B, Peine A, Östlund B. The importance of user involvement: a systematic review of involving older users in technology design. Gerontologist. (2020) 60:e513-23. doi: 10.1093/geront/gnz163

55. Bazzano AN, Martin J, Hicks E, Faughnan M, Murphy L. Human-centred design in global health: a scoping review of applications and contexts. PloS ONE. (2017) 12:e0186744-e. doi: 10.1371/journal.pone.0186744

56. Kensing F, Blomberg J. Participatory design: issues and concerns. Comp Support Cooperat Work. (1998) 7:167-85. doi: 10.1023/A:1008689307411

57. Blomberg J, Giacomi J, Mosher A, Swenton-Wall P. Ethnographic field methods and their relation to design. Participat Des Principles Pract. (1993) 7:123-55. doi: 10.1201/9780203744338-7

58. Grudin J. Why CSCW applications fail: problems in the design and evaluationof organizational interfaces. In: Proceedings of the 1988 ACM Conference on Computer-Supported Cooperative Work; Portland, OR: Association for Computing Machinery (1988). p. 85-93.

59. Barros A, de Rêgo S, Antunes J, editors. Aspects of human-centred design in HCI with older adults: experiences from the field. In: 5th International Conference on Human-Centred Software Engineering (HCSE). Paderborn: Springer (2014).

60. Zhao J, Zeng Z, Yu J, Xu J, Chen P, Chen Y, et al. Effect of main family caregiver's anxiety and depression on mortality of patients with moderate-severe stroke. Sci Rep. (2021) 11:2747. doi: 10.1038/s41598-02181596-8

61. Wilkinson C, Cornish K. An overview of participatory design applied to physical and digital product interaction for older people. Multimodal Technol Interact. (2018) 2:79. doi: 10.3390/mti2040079

62. Spinuzzi C. The methodology of participatory design. Tech Commun. (2005) 52:163-74

63. Harrington C, Erete S, Piper AM. Deconstructing communitybased collaborative design: towards more equitable participatory design engagements. Proc ACM Hum-Comput Interact. (2019) 3:1-25. doi: $10.1145 / 3359318$

64. Mohr DC, Lyon AR, Lattie EG, Reddy M, Schueller SM. Accelerating digital mental health research from early design and creation to successful implementation and sustainment. J Med Internet Res. (2017) 19:e153. doi: $10.2196 /$ jmir. 7725

65. Juristo N, Moreno AM, Sanchez-Segura M-I. Analysing the impact of usability on software design. J Syst Softw. (2007) 80:1506-16. doi: 10.1016/j.jss.2007.01.006

66. Bratteteig T, Bødker K, Dittrich Y, Mogensen PH, Simonsen J. Organising principles and general guidelines for Participatory Design Projects. Routledge International Handbook of Participatory Design. New York, NY: Routledge (2013). p. 117-44.

67. Robertson T, Wagner I. Ethics: Engagement, Representation and Politics-In-Action. Routledge International Handbook of 
Participatory Design. New York, NY: Routledge (2013). p. 64-85.

68. Brandt E, Binder T, Sanders EB. Tools and Techniques: Ways to Engage Telling, Making, and Enacting. Routledge International Handbook of Participatory Design. New York, NY: Routledge (2013). p. 145-81.

69. Mörtberg C, Bratteteig T, Wagner I, Stuedahl D, Morrison A. Methods that matter in digital design research. In: Wagner I, Bratteteig T, Stuedahl D, editors. Exploring Digital Design: Multi-Disciplinary Design Practices. London: Springer London (2010). p. 105-44.

70. Christiansen E. From "ethics of the eye" to "ethics of the hand" by collaborative prototyping. J Inf Commun Ethics Soc. (2014) 12:39. doi: 10.1108/JICES-11-2013-0048

71. Bødker K, Kensing F, Simonsen J. Participatory Design in Information Systems Development. Reframing Humans in Information Systems Development. London: Springer (2010). p. 115-34.

72. Schuurman D, De Marez L, editors. Living labs: a structured approach for implementing open and user innovation. In: Proceedings of the 13th Annual Open and User Innovation Conference. Lisbon (2015).

73. Andersen TO, Bansler JP, Kensing F, Moll J. From prototype to product: making participatory design of mhealth commercially viable. In: Kanstrup
AM, Bygholm A, Bertelsen P, editors. Participatory Design \& Health Information Technology. IOS Press (2017). p. 95-112.

74. Hossain M, Leminen S, Westerlund M. A systematic review of living lab literature. J Clean Prod. (2019) 213:976-88. doi: 10.1016/j.jclepro.2018.12.257

75. Guzmán JG, del Carpio AF, Colomo-Palacios R, de Diego MV. Living labs for user-driven innovation: a process reference model. Res Technol Manag. (2013) 56:29-39. doi: 10.5437/08956308X 5603087

Conflict of Interest: The authors declare that the research was conducted in the absence of any commercial or financial relationships that could be construed as a potential conflict of interest.

Copyright $\odot 2021$ Lobo, Frølich, Rasmussen, Livingston, Grundy, Abdelrazek and Kensing. This is an open-access article distributed under the terms of the Creative Commons Attribution License (CC BY). The use, distribution or reproduction in other forums is permitted, provided the original author(s) and the copyright owner(s) are credited and that the original publication in this journal is cited, in accordance with accepted academic practice. No use, distribution or reproduction is permitted which does not comply with these terms. 